\title{
Cyclic loading response of monopile foundations in cohesionless soils
}

\author{
C.N. Abadie \& B.W. Byrne \\ University of Oxford, United-Kingdom
}

\begin{abstract}
Most offshore wind farms around Europe are being constructed with monopile foundations. Whilst there is some knowledge transfer from oil and gas design there are also a number of key differences, which means new design guidelines are needed. This paper outlines some of the key issues confronting the offshore wind turbine foundation designer and concentrates on the effect of cyclic loading. It presents experimental results from a series of $1 \mathrm{~g}$ model tests, following on from the work of Leblanc et al. (2010a). The tests aim at further exploring a framework for calculating the long term accumulated rotation. The results confirm the phenomenological laws proposed by Leblanc et al. (2010a) for the accumulated rotation and the cyclic secant stiffness. The results also highlight that in addition to the relative density and load characteristics, the accumulated rotation and the secant stiffness appear to be dependent on the sand properties.
\end{abstract}

\section{INTRODUCTION}

The design of offshore piles has been developed over many years by the oil and gas industry. In the absence of guidelines for offshore wind turbine structures, designers use the practices for conventional fixed offshore platform, such as those published by the American Petroleum Institute API (2011). For lateral loading of piles these rely on the $p-y$ approach, introduced by Reese et al. (1974) and O'Neill \& Murchison (1983). In this method, the soil-pile interaction is modelled by a series of independent springs, characterised by a non-linear empirical behaviour law between the lateral pile deflection and the soil resistance. This method was originally calibrated against full-size pile tests in sand, under lateral loading. The piles were long, slender and flexible and intended to replicate those used for oil and gas platform foundations. This empirical approach appears to be reasonably efficient since few platform pile foundation failures have been recorded.

However, offshore wind turbine piles have both a different geometry and loading conditions compared to oil and gas structure foundations. Thus, it is becoming apparent that the current $p-y$ methodology may not be appropriate for the design of offshore wind turbine monopiles, without additional calibration (Kallehave et al. 2012), and particularly for the effects of long-term cyclic lateral loading (Long \& Vanneste 1994).
This paper outlines current design guidance used for offshore wind turbine monopiles, and presents a new methodology being proposed to address the issue of cyclic lateral loading. Additional experimental results are presented to further validate the methodology.

\section{CURRENT DESIGN METHODOLOGIES}

\subsection{Guidelines from the American Petroleum Institute}

The current guidelines for the design of offshore wind turbine piles (for example DNV 2011) are based around the standards published for the design of oil and gas structures, such as those by the American Petroleum Institute (API 2011). The recommended relationship between the lateral pile deflection $y$ and the soil resistance $p$ is:

$\mathrm{p}=A \mathrm{p}_{\mathrm{u}} \tanh \left(\frac{K_{0} y}{A p_{u}}\right)$

where $p_{u}$ is the static ultimate lateral pile resistance, $A$ is an empirical parameter that takes into account the loading type (static or cyclic) and $K_{0}$ is the initial reaction modulus of the soil which depends on the angle of friction $\phi$, the relative density $R_{d}$ and the depth $z$.

For the case of cyclic loading, $A$ is taken to be 0.9 . However, the value of $A$ stays the same irrespective 
of the number of cycles, $N$. Many authors underline this gap in the method (Little \& Briaud 1988, Long \& Vanneste 1994, Verdure et al. 2003) and propose to modify Equation 1 in order to integrate the number of cycles $N$ into the model. One such methodology is the degradation stiffness model where a reduction factor is applied to the soil reaction modulus (e.g. Reese et al. 1974, O'Neill \& Murchison 1983, Long \& Vanneste 1994, Verdure et al. 2003). A key problem in the development of these models is that the data are usually limited to small numbers of cycles $(<500)$, and may therefore not be easily extrapolated. This method is not discussed further in this paper but the results presented could be recast within in this framework.

\subsection{Framework of response for long-term cyclically loaded piles, Leblanc et al. (2010a)}

More recently, a framework of response for the behaviour of monopile foundations subjected to large numbers of cycles (over 8000) has been introduced by Leblanc et al. (2010a). This work was based on a comprehensive laboratory testing program.

The loading is characterized in terms of two parameters: the magnitude $\zeta_{b}$ and amplitude $\zeta_{c}$ (Equations 2 and 3 ).

$$
\begin{gathered}
\zeta_{b}=\frac{M_{\text {max }}}{M_{R}} \\
\zeta_{c}=\frac{M_{\text {min }}}{M_{\text {max }}}
\end{gathered}
$$

where $M_{\min }$ and $M_{\max }$ is the minimum and maximum moment over a load cycle and $M_{R}$ is the static moment capacity of the pile. $\zeta_{b}$ ranges between 0 and 1 when $\zeta_{c} \in[-1,1] . \zeta_{c}=1$ for a static test, 0 for a oneway loading test and -1 for a two way loading test.

The test programme involved a laboratory scale monopile in dry Yellow Leighton Buzzard sand at two different relative densities $\left(R_{d}=4 \%\right.$ and $R_{d}=38$ $\%)$, subjected to a wide range of load conditions $\left(\zeta_{b}\right.$ and $\zeta_{c}$ ). The results led to the identification of laws characterizing the evolution of the pile tilt as well as the soil stiffness with cycle number. Leblanc et al. (2010b) completed this framework by an analysis of the effect of random cyclic loading on the pile response, though this is not discussed here.

\subsubsection{Accumulated displacement over the cycles}

Leblanc et al. (2010a) evaluated the displacement of the pile via the magnitude of rotation $\Delta \theta=\theta_{N}^{\max }$ $\theta_{0}{ }^{\max }$ caused by cyclic loading. They related $\Delta \theta$ to the rotation $\theta_{S}$ that would occur in a static test when the applied load is equal to the maximum cyclic load. Their test results show that the accumulated ro- tation follows a power law relationship with the number of cycles, according to Equation 4.

$\frac{\Delta \theta}{\theta_{S}}=T_{b}\left(\zeta_{b}, R_{d}\right) \cdot T_{c}\left(\zeta_{c}\right) \cdot N^{\alpha}$

Here $T_{b}$ and $T_{c}$ are dimensionless empirical functions depending on the relative density $R_{d}$ and the load characteristics, whilst $\alpha$ is an empirical evolution parameter equal to 0.31 .

\subsubsection{Evolution of the stiffness}

The test results also highlight a logarithmic evolution of the cyclic secant stiffness with the number of cycles given by Equation 5 .

$\tilde{k}_{N}=\tilde{k}_{b}\left(\zeta_{b}\right) \cdot \tilde{k}_{c}\left(\zeta_{c}\right)+C \cdot \ln (N)$

In this equation, $\tilde{k}_{N}=k_{N} / L^{5 / 2} D \sqrt{p_{a} \gamma^{\prime}}$ is the nondimensional stiffness, $\tilde{k}_{b}$ and $\tilde{k}_{c}$ are empirical functions that depend on the load characteristics. $C$ is a dimensionless empirical constant equal to 8.02.

\subsection{Definition of the stiffness}

The analysis of cyclic phenomena requires a careful definition of the term stiffness. This clarification is essential and is illustrated in Figure 1.

\subsubsection{Absolute stiffness $K$}

The absolute stiffness $K_{N}$ is the parameter that relates the soil state at cycle $N$ to the initial state. It describes the progressive evolution of the soil-pile interaction and is defined as the ratio of applied load versus the absolute deflection of the pile.

\subsubsection{Cyclic secant stiffness $k$}

The cyclic secant stiffness $k_{N}$ characterizes the state of the soil-pile interaction after $N$ cycles, and is de-

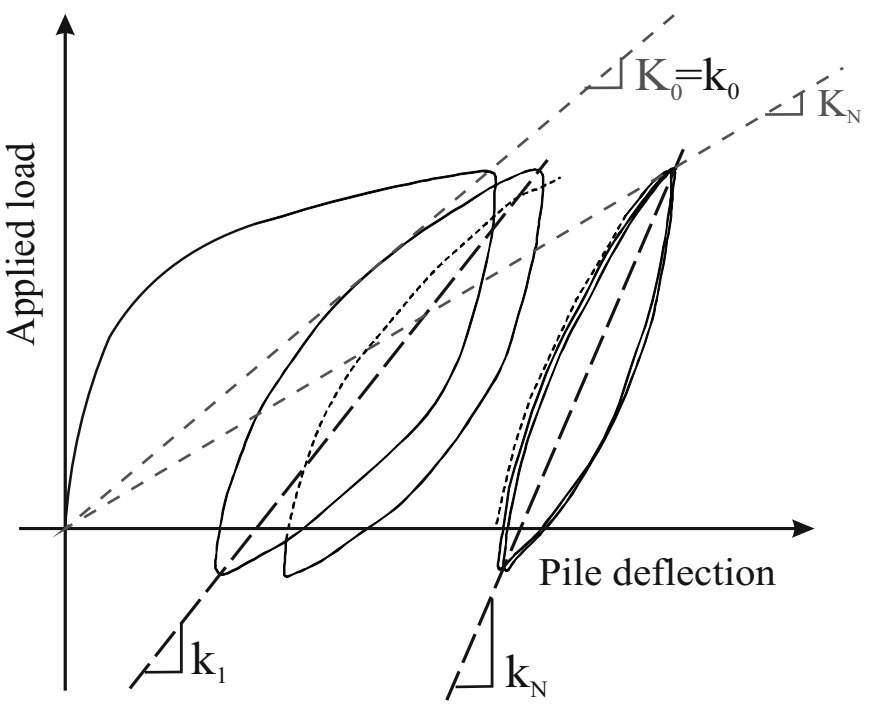

Figure 1. Definition of the absolute $\left(K_{i}\right)$ and cyclic secant $\left(\mathrm{k}_{\mathrm{i}}\right)$ stiffness 
scribed by Equation 5. Its evolution is critical since it drives the change in natural frequency of the structure with cycle number (Byrne 2011, Equation 6).

$$
f_{n N}=\frac{1}{2 \pi} \sqrt{\frac{1}{m \cdot\left(\frac{h^{3}}{3 E I}+\frac{h^{2}}{k_{N}}\right)}}
$$

Here, $m$ is the mass and $h$ the height of the centre of gravity of the superstructure. $E$ and $I$ are the young's modulus and second moment of area of the superstructure respectively. In this paper, the evolution of the secant stiffness is addressed, though the results could be interpreted to provide information about the absolute stiffness.

\section{EXPERIMENTAL MODEL}

\subsection{Experimental equipment}

The laboratory tests were carried out with a rig developed by Rovere (2004). It is based on a suspended mass system that enforces a cyclic lateral load at an eccentricity $e$ from the mud line (Figure 2).

The mass $m_{3}$ balances the weight of the main beam and the motor $\left(m_{1}=m_{2}=0\right)$. The values of $m_{1}$ and $m_{2}$ directly set the value of the sinusoidal force $H(t)=H_{0}+H_{a} \cdot \sin (\omega t)$ applied at the top of the pile. When the motor is running, it carries $m_{1}$ along a circular path which makes the gravity centre of the main beam change sinusoidally. The wire connecting the main beam and the pile transmits loads to the top of the pile. The pulsation is enforced by the motor frequency $(f=0.106 \mathrm{~Hz})$. This rig offers the possibility of applying thousands of repeatable cycles in a realistic time.

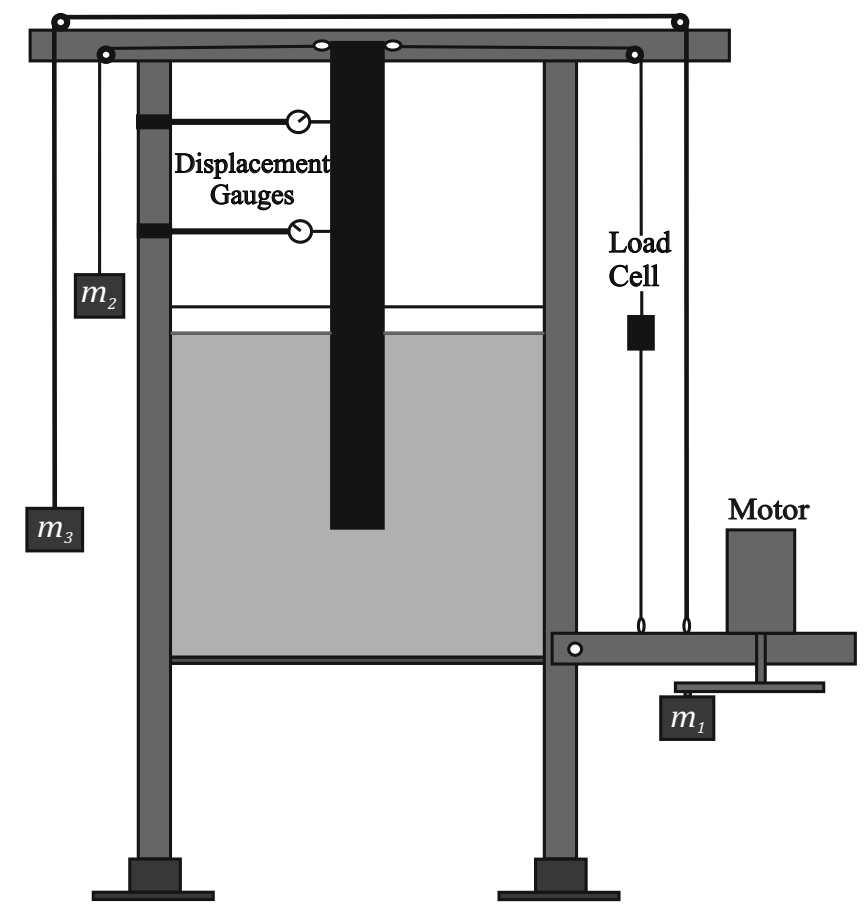

Figure 2. Schematic of the experimental rig
The values of the loading and pile dimensions have been chosen according to the non-dimensional framework introduced by Leblanc et al. (2010a). As an illustration, two non-dimensional parameters that result from this model and are used in this paper are given by Equations 7 and 8 .

$\tilde{\theta}=\theta \cdot \sqrt{\frac{p_{a}}{L \gamma^{\prime}}}$

$\tilde{M}=\frac{M}{L^{3} D \gamma^{\prime}}$

Where $p_{a}$ is the atmospheric pressure, $\gamma$ the effective soil unit weight and where non-dimensional parameters are denoted by a tilde.

The size of the pile is scaled to $1 / 50$ of a typical 2 MW offshore wind turbine monopile (Table 1), although it is geometrically similar to larger wind turbine piles. The dimensions mean that it is stiff, compared with the soil stiffness and it is made of copper. The dimensions of the sand container are $600 \mathrm{~mm} x$ $600 \mathrm{~mm} \times 527 \mathrm{~mm}$ which allows for a clearance of at least $2.75 \mathrm{D}$ between the pile and the container wall. This minimises the disturbing effect of the walls on the soil-pile interaction.

\subsection{Test programme}

The results presented in this paper are aimed at exploring the effect of the sand particle size on the framework introduced by Leblanc et al. (2010a).

For this purpose, tests were carried out with two different sands, Yellow Leighton Buzzard 14/25 (YLB) and RedHill 110 (RH110). Both are very uniform silica sand with an angular grain shape. The major difference between them is their particle size (Table 2). The sands were tested dry so that only the drained behaviour was investigated.

For both sands, the samples were prepared by carefully pouring the sand from a very low drop height with a scoop. This method enables to prepare

Table 1. Properties of the copper pile

\begin{tabular}{|l|l|}
\hline Property & value \\
\hline Pile diameter $(\mathrm{mm})$ & 80 \\
Thickness $(\mathrm{mm})$ & 2.0 \\
Penetration depth $(\mathrm{mm})$ & 360 \\
Load eccentricity $(\mathrm{mm})$ & 430 \\
\hline
\end{tabular}

Table 2. Properties of YLB (Schnaid 1990) and RH110 (Villalobos et al. 2005, Schupp 2009)

\begin{tabular}{|l|c|c|}
\hline Property & YLB & RH110 \\
\hline Mean particle size $\mathrm{D}_{50}(\mathrm{~mm})$ & 0.80 & 0.137 \\
Specific Gravity $\mathrm{G}_{\mathrm{S}}$ & 2.65 & 2.63 \\
Minimum dry unit weight $\gamma_{\min }\left(\mathrm{kN} / \mathrm{m}^{3}\right)$ & 14.65 & 12.64 \\
Maximum dry unit weight $\gamma_{\max }\left(\mathrm{kN} / \mathrm{m}^{3}\right)$ & 17.58 & 15.72 \\
Critical angle of friction $\phi_{\mathrm{cr}}($ degrees $)$ & 34.3 & 36 \\
Coefficient of uniformity $\mathrm{C}_{\mathrm{u}}$ & 1.35 & 1.82 \\
Curvature coefficient $\mathrm{C}_{\mathrm{d}}$ & 0.91 & 1.05 \\
\hline
\end{tabular}


Table 3. Test Programme

\begin{tabular}{|l||l|c|c|c|c|c|c|}
\hline No. & Type of test & Sample & $d_{50}(\mathrm{~mm})$ & $R_{d}(\%)$ & $\zeta_{b}$ & $\zeta_{c}$ & $N$ \\
\hline 1 & Static & YLB & 0.80 & 4 & - & - & - \\
2 & Static & RH110 & 0.137 & 18 & - & - & - \\
3 & Cyclic, 1-way & YLB & 0.80 & 4 & 0.29 & 0 & 13400 \\
4 & Cyclic, 1-way & YLB & 0.80 & 4 & 0.37 & 0 & 15000 \\
5 & Cyclic, 1-way & YLB & 0.80 & 4 & 0.42 & 0 & 7400 \\
6 & Cyclic, 1-way & RH110 & 0.137 & 18 & 0.37 & 0 & 1000 \\
7 & Cyclic, 1-way & RH110 & 0.137 & 18 & 0.38 & 0 & 24100 \\
8 & Cyclic, 1-way & RH110 & 0.137 & 18 & 0.42 & 0 & 1000 \\
9 & Cyclic, 2-way & RH110 & 0.137 & 18 & 0.37 & -0.45 & 1000 \\
10 & Cyclic, 2-way & RH110 & 0.137 & 18 & 0.37 & -0.95 & 12000 \\
\hline
\end{tabular}

very loose sand samples with an average relative density of about $R_{d}=4 \%$ for Yellow Leighton Buzzard and $R_{d}=18 \%$ for RedHill 110 .

The test programme involved 2 static tests, 3 cyclic tests with YLB and 5 cyclic tests with RH110. The characteristics of the applied cyclic load were defined in terms of $\zeta_{b}$ and $\zeta_{c}$. The properties of each test have been summarized in Table 3 .

\section{RESULTS}

\subsection{Static moment capacity}

For each sand sample, a static test was carried out to determine the non-dimensional ultimate capacity of the pile $\tilde{M}_{R}$. This parameter is used as a reference for the choice of the load magnitude for the cyclic tests (Equation 2). The results of the static tests are given in Figure 3.

The failure limit of a laterally loaded pile is not trivial since no clear failure behaviour appears on the curve (Figure 3). The guidelines (DNV, 2011) advise to determine the value of $\tilde{M}_{R}$ via, first, a theoretical calculation of the lateral pile resistance and, second, by an evaluation of the lateral displacement at the pile head. Since the pile is very stiff, the theoretical lateral pile resistance is too high to be chosen as a limit. It would indeed lead to a pile-head displacement of over $50 \%$ of the diameter

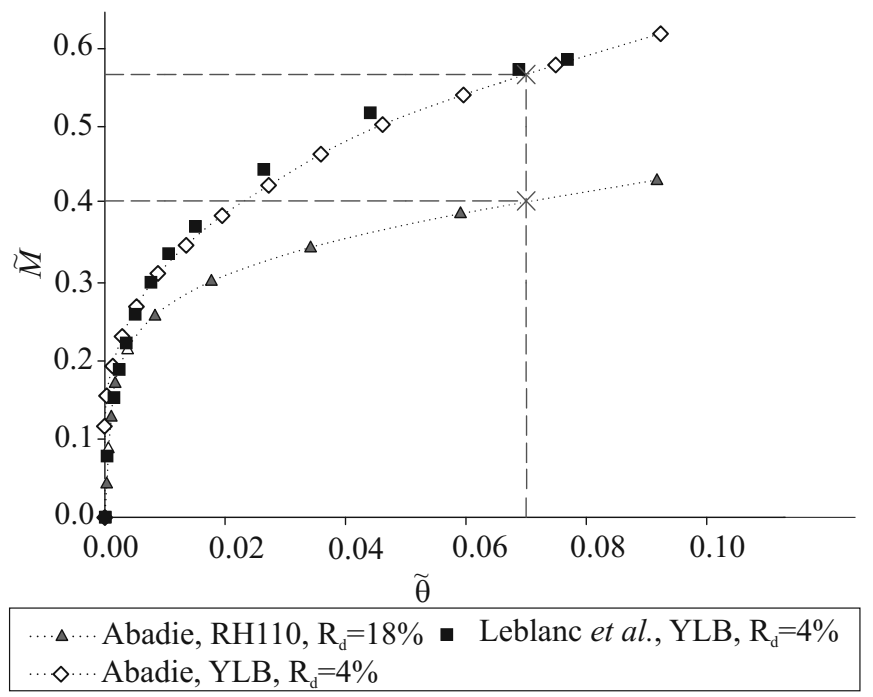

Figure 3. Results of the static tests of the pile. The failure limit of the pile-head deflection has therefore been fixed to $5 \%$ of the diameter of the pile, which is equivalent to a non-dimensional rotation of $\widetilde{\theta}=0.07$ for both sand samples. With this definition $\tilde{M}_{R}=0.40$ and $\tilde{M}_{R}=0.57$ for RH110 and YLB respectively.

\subsection{Evolution of the accumulated rotation}

Figure 4 illustrates the influence of the sand particle size on the framework introduced by Leblanc et al.. On graphs 4.a and 4.b, the dotted lines have been obtained using Equation 4 with $\alpha=0.31$. They show a good fit to the results and prove that the value of $\alpha=$ 0.31 is well-adapted for the results obtained with RH110. Therefore, the value of $\alpha$ appears independent of the particle size, the load characteristics and the relative density.

Figures 4.c and 4.d display the evolution of $T_{b}$ and $T_{c}$ with the load characteristics, relative density and particle size. Given that $T_{c}=1$ when $\zeta_{c}=0, T_{b}$ and $T_{c}$ can be analysed separately by carrying out one-way loading tests, and then two-way loading tests for the same value of $\zeta_{b}$. Figure 4.c clearly shows that $T_{b}$ depends on the relative density and the particle size. Though, more tests would be required to fit a mathematical expression for $T_{b}$. Figure 4.d shows that $T_{c}$ is rather independent of the sample properties and solely varies with $\zeta_{c}$.

\subsection{Evolution of the cyclic secant stiffness}

Figure 5 shows the influence of the sand particle size on the cyclic secant stiffness. The dotted lines on Figures 5.a, b have been fitted using Equation 5 with $C=8.02$. The trend lines show a good fit to the test results and highlight that the phenomenological law proposed by Leblanc et al. (2010a) appears to describe the evolution of the secant stiffness. In addition, the value $C=8.02$ does not show to depend on the sand particle size.

Figures 5.c and 5.d display the results obtained for the functions $\tilde{k}_{b}$ and $\tilde{k}_{c}$. These graphs show that the function $\tilde{k}_{b}$ depends on the sand particle size when the function $k_{c}$ is independent of this parameter. Therefore, the empirical law proposed by Leblanc et al. (2010a) for $\widetilde{k}_{c}$ is appropriate but com- 
plementary tests are necessary in order to investigate $\tilde{k}_{b}$ in details.

\subsection{Limitations}

The framework presented in this paper relies on the assumption that the results obtained for the initial few thousands of cycles can be extrapolated to millions of cycles. Moreover, the completed work only accounts for unidirectional loading in a single layer of dry sand. Further work would involve the investigation of the response of the pile in more realistic conditions. Data from full-scale monitored monopiles would also be useful for the validation of the model.

\section{CONCLUSION}

A series of $1 \mathrm{~g}$ tests have been conducted in order to

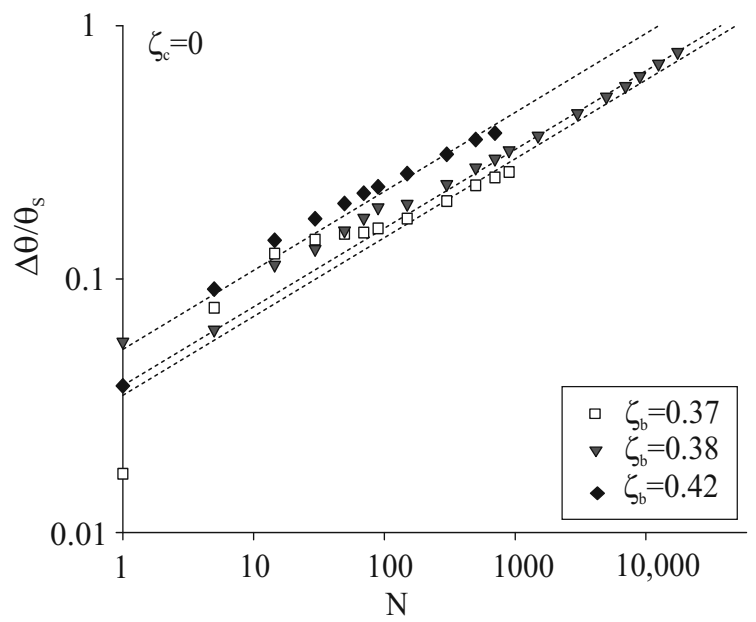

(a)

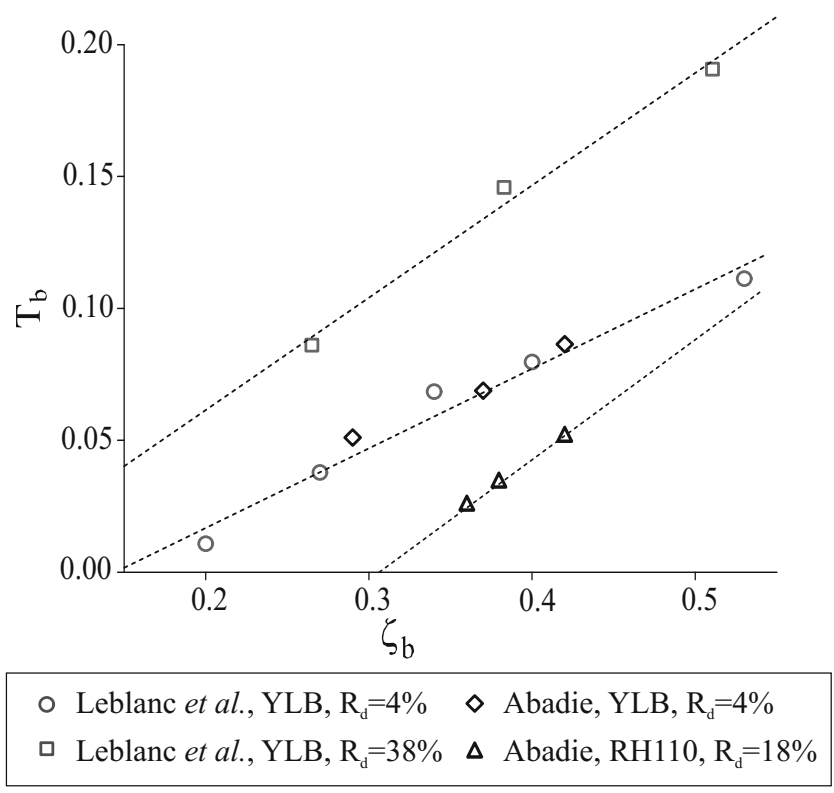

(c) supplement Leblanc et al.'s (2010a) research as well as the current methodologies used for the design of piles subjected to lateral cyclic loading. The tests involved 1,000 to 24,000 cycles in dry sand. The nondimensional framework developed by Leblanc et al. (2010a) has been used in order to properly scale the laboratory model.

The test results show that the accumulated rotation of the pile is well fitted by the exponential law proposed by Leblanc et al. The results also confirm the logarithmical law proposed for the evolution of the cyclic secant stiffness. They demonstrate that both the accumulated rotation and the secant stiffness depend on the sand particle size.

This framework constitutes a good approach for improving the current guidelines concerning the design of offshore wind turbine piled foundations. It provides new data concerning the response of the pile to large number of cycles in a range of site conditions.

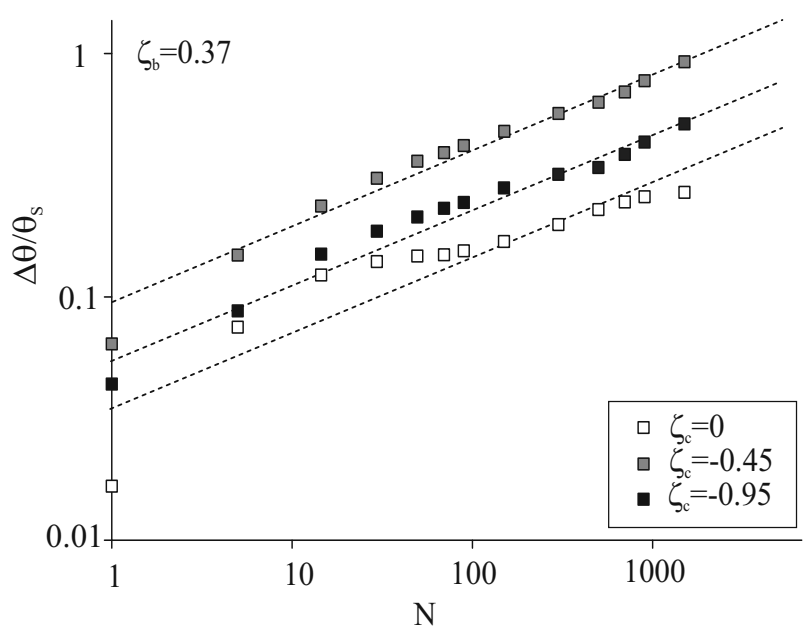

( b )

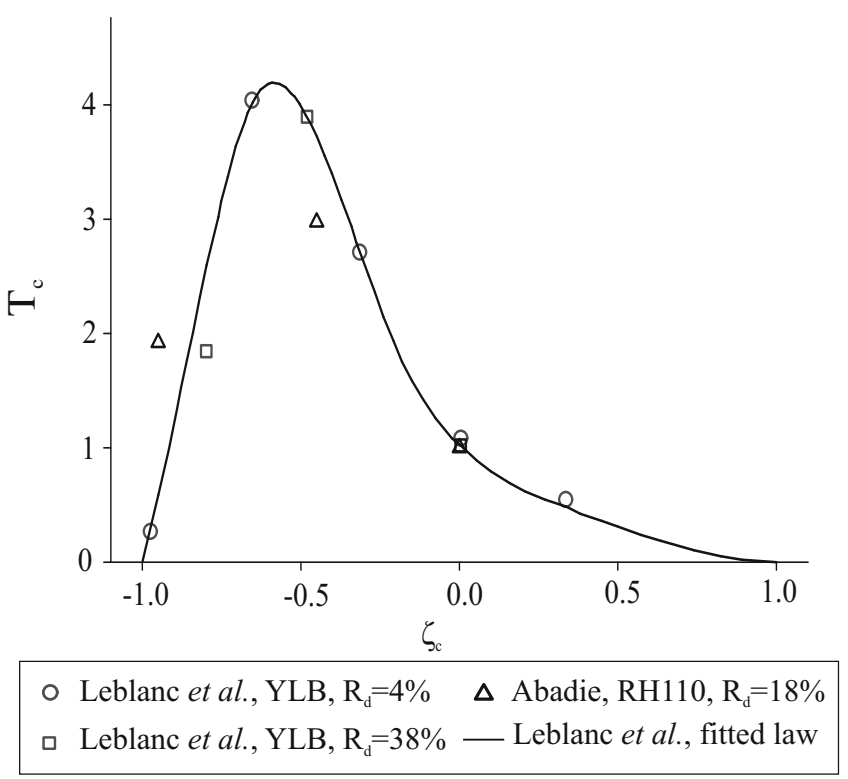

(d)

Figure 4. Measured accumulated rotation as a function of $N$, particle size and load characteristics - Results of the one-way (a) and two-way (b) loading tests with RH110 (dotted lines obtained from Equation 4) - Functions relating $T_{b}(\mathrm{c})$ and $T_{c}(\mathrm{~d})$ to the particle size 


\section{REFERENCES}

American Petrolum Institute (API) and International Organization for Standardization (ISO). 2011. Geotechnical and Foundation Design Considerations for Offshore Structures. ANSI/API Specification RP 2GEO. Washington DC: API.

Byrne, B.W. 2011. Foundation Design for Offshore Wind Turbines. Géotechnique Lecture 2011, Institution of Civil Engineers.

Det Norske Veritas AS (DNV). 2011. Offshore standards: Design of offshore wind turbine structures. DNV-OS-J101. Hellerup, Denmark: DNV.

Leblanc C., Houlsby G.T. \& Byrne B.W. 2010a. Response of stiff piles in sand to long-term cyclic lateral loading, Géotechnique 60(2): 79-90.

Leblanc C., Houlsby G.T. \& Byrne B.W. 2010b. Response of stiff piles to random two-way lateral loading. Géotechnique 60(9): 715-721.

Little, R. \& Briaud, J.L. 1988. Cyclic horizontal load tests on six piles in sands at Houston Ship Channel. Research report 5640 to USAE Waterways Experiment Station. Texas A\&M University, USA.

Long, J.H. \& Vanneste G. 1994. Effects of cyclic lateral loads on piles in sand. J. Geotech. Engng 120(1): 225-244.

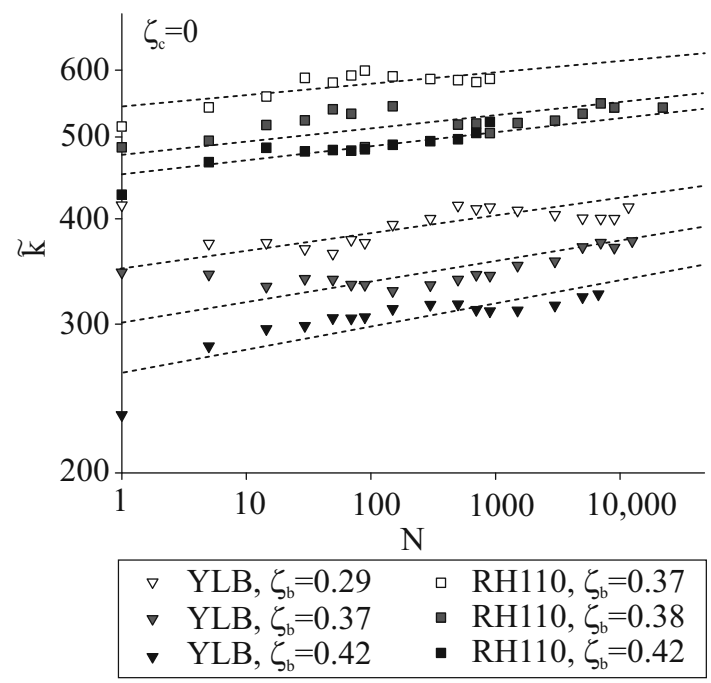

( a )

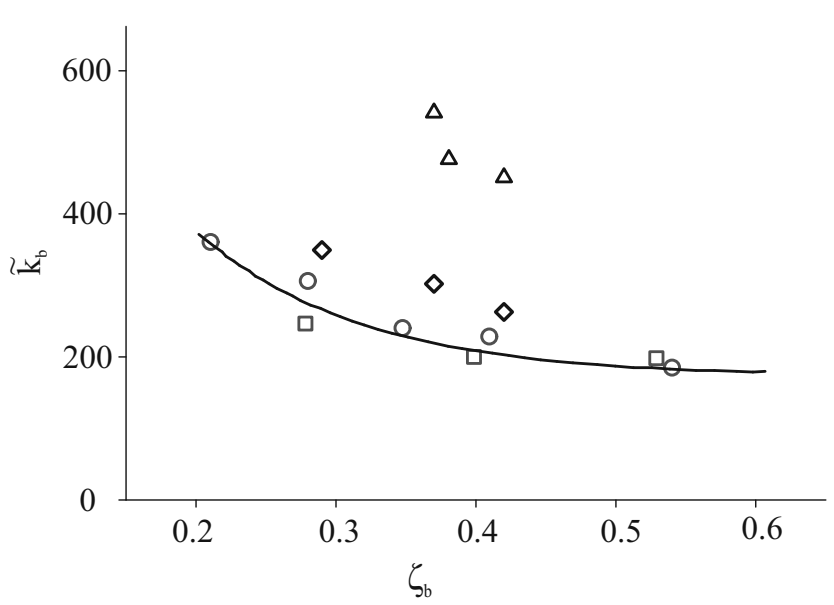

○ Leblanc et al., YLB, $\mathrm{R}_{\mathrm{d}}=4 \%$ ○ Abadie, $\mathrm{YLB}, \mathrm{R}_{\mathrm{d}}=4 \%$

$\square$ Leblanc et al., YLB, $\mathrm{R}_{\mathrm{d}}=38 \% \Delta$ Abadie, RH110, $\mathrm{R}_{\mathrm{d}}=18 \%$

( c )
Kallehave D., Leblanc Thilsted C., Liingaard M.A. 2012. Modification of the API p-y formulation of initial stiffness of sand. Proc. 7th Int. Conf. Offshore Site Investigation and Geotechnics. London, UK.

O’Neill M.W. \& Murchison, J.M. 1983. An evaluation of p-y relationships in sands. Research Rep. No. GT-DF02-83. University of Houston, Texas, USA.

Reese, L.C., Cox W.R. \& Koop, F.D. (1974). Analysis of laterally loaded piles in sand. Proc. 6th Offshore Tech. Conf. 2079. Houston, Texas, USA.

Rovere, M. 2004. Cyclic loading test machine for caisson suction foundations. Master thesis. Centrale Lille, France \& Polytechnico di Milano, Italy.

Schnaid, F. 1990. A study of the cone-pressuremeter test in sand. DPhil Thesis, University of Oxford, UK.

Schupp, J. 2009. Upheaval Buckling and Flotation of Buried Offshore Pipelines. DPhil Thesis, University of Oxford, UK.

Verdure, L., Garnier J. \& Levacher, D. 2003. Lateral cyclic loading on single piles in sand. IJPMG 3: 17-28.

Villalobos, F.A., Byrne, B.W. \& Houlsby, G.T. 2005. Moment loading of caissons installed in saturated sand. Proc. of the Int. Symp. on Frontiers in Offshore Geotechnics. Perth, Australia.

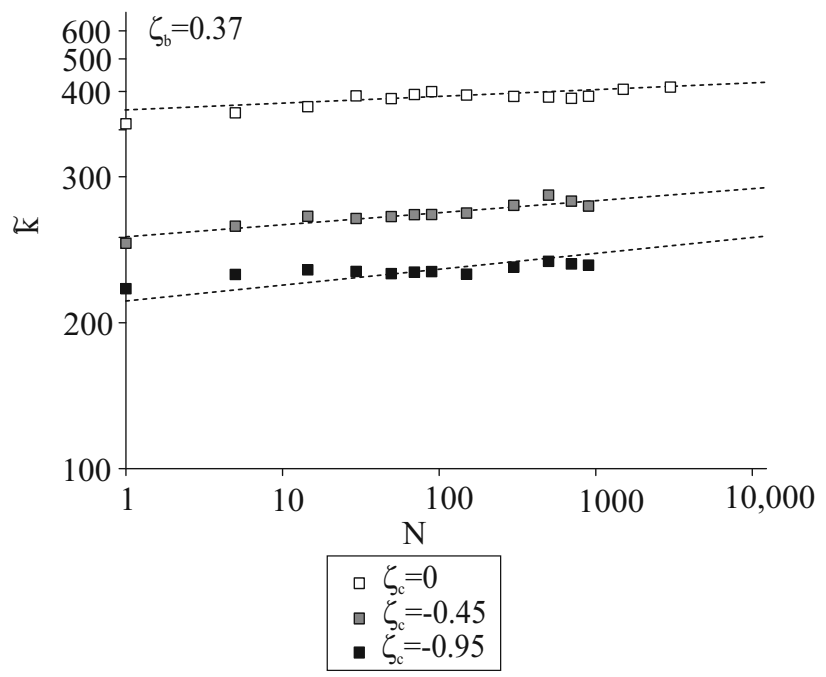

(b)

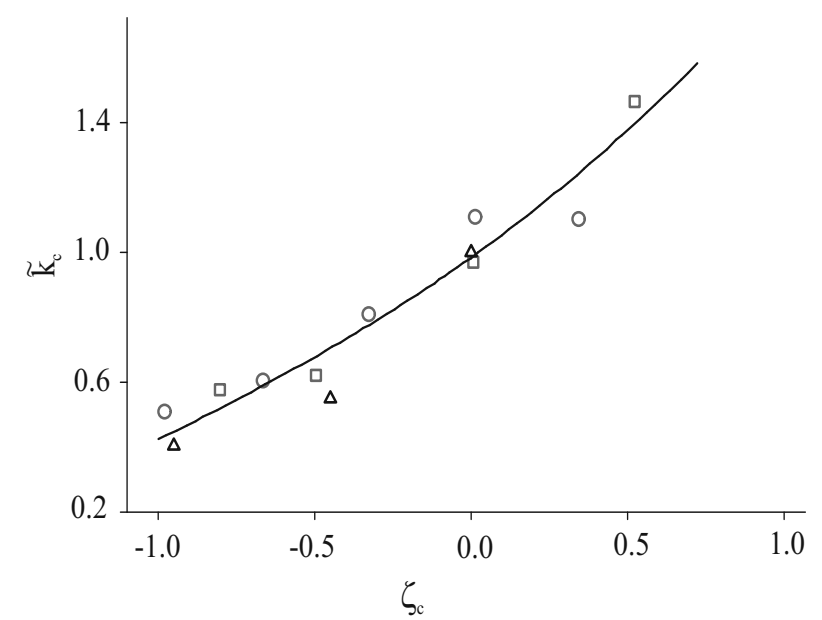

○ Leblanc et al., $\mathrm{YLB}, \mathrm{R}_{\mathrm{d}}=4 \% \quad \Delta$ Abadie, $\mathrm{RH} 110, \mathrm{R}_{\mathrm{d}}=18 \%$ 口 Leblanc et al., YLB, $\mathrm{R}_{\mathrm{d}}=38 \%$ — Leblanc et al., fitted law

( d )

Figure 5. Measured cyclic secant stiffness as a function of $N$, particle size and load characteristics - Results of the one-way (a) and two-way (b) loading tests with RH110 (dotted lines obtained from Equation 5) - Functions relating $\widetilde{k}_{b}(\mathrm{c})$ and $\widetilde{k}_{c}(\mathrm{~d})$ to the particle size 